\title{
Analysis of the Promoting Effect of the Mode of Industrial Technology Research Institute on Technology Transfer
}

\author{
LI Hongyu ${ }^{1,2}$ \\ 1 Department of Finance \& Economics, Jinan campus of Shandong University of Science and \\ Technology, P.R. China, 250031 \\ 2 School of Economics and Management, Beijing Jiaotong University, P.R. China, 100044 \\ lihongyu0725@126.com
}

Keywords: Industrial Technology Research Institute (ITRI), Technology transfer, Innovation, Promoting effect.

\begin{abstract}
The global economy has entered a new economic era with innovation as the first driving factor, and the acceleration of innovation resources has become a global trend. Technology transfer is the essence of innovation globalization. Compared with developed countries, China's current technology transfer efficiency is relatively low, which lacks the effective organization model to promote the effective cooperation between industries and universities, and the effective mode to promote transformation of scientific and technological achievements. This paper takes Taiwan Industrial Technology Research Institute (TITRI) as a case study, and deeply analyzes its organization management mode, operation mechanism, technology development mode and talent training mode, which points out that the Industrial Technology Research Institute (ITRI) model has obvious effect on promoting the efficiency of technology transfer in China, so we should actively rely on the mode of ITRI to improve science \& technology and economic competitiveness of China.
\end{abstract}

\section{Research background}

China's current technology transfer and application capabilities are seriously inadequate. It has more than 1 thousand existing colleges and universities, with certain scientific research strength. Every year, there are 30 thousand scientific research achievement endowed with Department (Provincial) level or above, among which about 20 thousand result from colleges and universities. But scientific research results that are transferred smoothly, stable in production with a certain scale accounted for only $20 \%$, and that eventually forms an industry accounted for only about $5 \%$ or so, far below the average of $50 \%$ in developed countries. The reasons are as follow: first, lacking organizational model that can promote effective cooperation between industries and universities. There are various deficiencies in organization which takes governments, universities, research institutes and enterprises as a main body to promote transformation of scientific and technological achievements. Second, it lacks effective model to promote transformation of scientific and technological achievements. At present, the existing models lack flexible market capacity, and technical maturity is not enough, resulting in the success rate of industrialization of technical achievements is not high. Technology transfer can help scientific research institutions and enterprises realize the industrialization of scientific and technological achievements and obtain economic benefits. At the same time, it has become an important way for a country or region to accelerate scientific \& technological progress and enhance economic strength \& international competitiveness. Therefore, the study of technology transfer problem has a particularly important significance.

\section{Definition of related concepts}

2.1 Technology transfer. Technology transfer refers to the transfer of technology from one place to another. It includes technology transfer between countries, and includes transfers from the technology development sector (research institutions) to the use sector (business and business sector), and transfer between use department as well. 
Technological innovation and technology transfer are two main paths of technological progress. A country is to achieve and maintain a leading position in technology mainly through technological innovation. The rate of technological innovation, not only comes from the technology generated through innovation, but are also closely related with the ability to gather, share and transfer of science and technology resources, whose importance has been widely recognized. Technology transfer accelerates the transformation of scientific and technological achievements and the industrialization of high and new technology. The United States has done research on technology transfer, which suggests: The average income of enterprises through technology transfer is 55\%, but the average return through technological innovation is only $22 \%$.

2.2 Industrial Technology Research Institute. ITRI is a new type of organization on technology development and transformation. It has played an active role in realizing technology transfer, promoting the upgrading of regional industrial structure and promoting the further development of regional economy. Its characteristics are closely linked with contacting government, enterprises, universities and research institutes, emphasizing the innovation cooperation between enterprises and universities, scientific research institutions, emphasizing government support, guidance and support, making clear division and orientation of government, enterprises, universities and research institutes, so as to strengthen cooperation between the parties.

\section{Operation mechanism of Industrial Technology Research Institute}

3.1 Operation mode. The operation mode of the ITRI is "the government promotes with the University Institute dominant, the enterprise supports with the international cooperation, the marketability operation, the socialized service", aiming to realize the independent innovation of science and technology innovation system based on the ITRI, and then enter the whole social science and technology innovation system. The Institute of Industrial Technology mainly makes forward-looking generic technology research and development, and focuses on the application, focus on the commercialization of scientific and technological achievements, industrialization and marketization of applied research and development. After the success of the development, it provides technical transfer and technical services to enterprises through various ways.

3.2 Fund operation mode. The capital circulation of ITRI is mainly to attract social capital by market-oriented operation, including the construction of start-up funds and operating costs: Start-up funds generally are through the "government support, combining science and technology innovation funds with enterprises, social donations" way to be raised, embodying the characteristics of "publicity" and "autonomy" of ITRI; Operating funds are to be raised through efforts to build two technology growth and venture capital venture platforms (VC firms and Technology Transformation Fund). By transferring appropriate technology transfer funds, to cultivate the invention of ITRI into advanced technology and prototype products needed by enterprises.

3.3 Science and technology research and development model. ITRI is an open science and technology organization. In science and technology research and development, it mainly takes the following models: First, to undertake the government special plan for the industry that does not appear to accept the object of forward-looking generic technology. This kind of common technology contains high technical risk and market risk, and usually needs direct government funding. Second, it makes a second conversion on the university and research institutions of scientific and technological achievements. Third, it cooperates with enterprises, and ITRI is to open the research direction and content and adhere to the principle of market orientation, according to the proposed research project of industry or enterprise, actively cooperate with the members of the alliance as well as make joint research and development of new technology.

3.4 Personnel training and using mode. ITRI mainly adopts the way of combining external introduction and internal training in personnel cultivating. On the one hand, it actively introduces high-tech innovation and entrepreneurial talents with true skills and genuine knowledge at home and abroad; On the other hand, in the process of talent growth, it cooperates with domestic and 
foreign well-known universities and research institutions, through the establishment of scientific and technological personnel exchange visits, exchange, training and joint training mechanism to train scientific research personnel.

Constructing scientific and technological achievements evaluation personnel database to collect and store four types of expert team: First, scientists, engineers team, who can convert a technology into a product or service; The second category is the marketing team, who can do research and screen the market to meet the needs of the products and services, and release the products and services to see who need them, who are willing to invest or business, all of which is equal to the capital socialization; The third kind of team is to help entrepreneurs experts, according to the choice of products and services, to provide a set of management model process; The fourth kind of team is financing experts, to help entrepreneurs butt VC, PE and other institutions.

\section{Case analysis----Taiwan Industrial Technology Research Institute}

4.1 Development profile. ITRI first appeared in Taiwan, China, and the nature of which is a public research institution of government established, non-profit, and dedicated to the application of technology services. In 1970s, Taiwan specially established the ITRI, basing on that Taiwan industry are mainly small and medium, with limited $R \& D$ resources and innovation capability, not being able to bear the risk of long-term innovation. The main tasks are: the development of industrial technology, diffusion of research results, the optimization of the industrial structure through the promotion and application, the improvement of industrial technology, the transformation and upgrading of traditional industries and emerging industries with government balance, and innovation promotion of hi-tech industry.

\subsection{Organization and management structure}

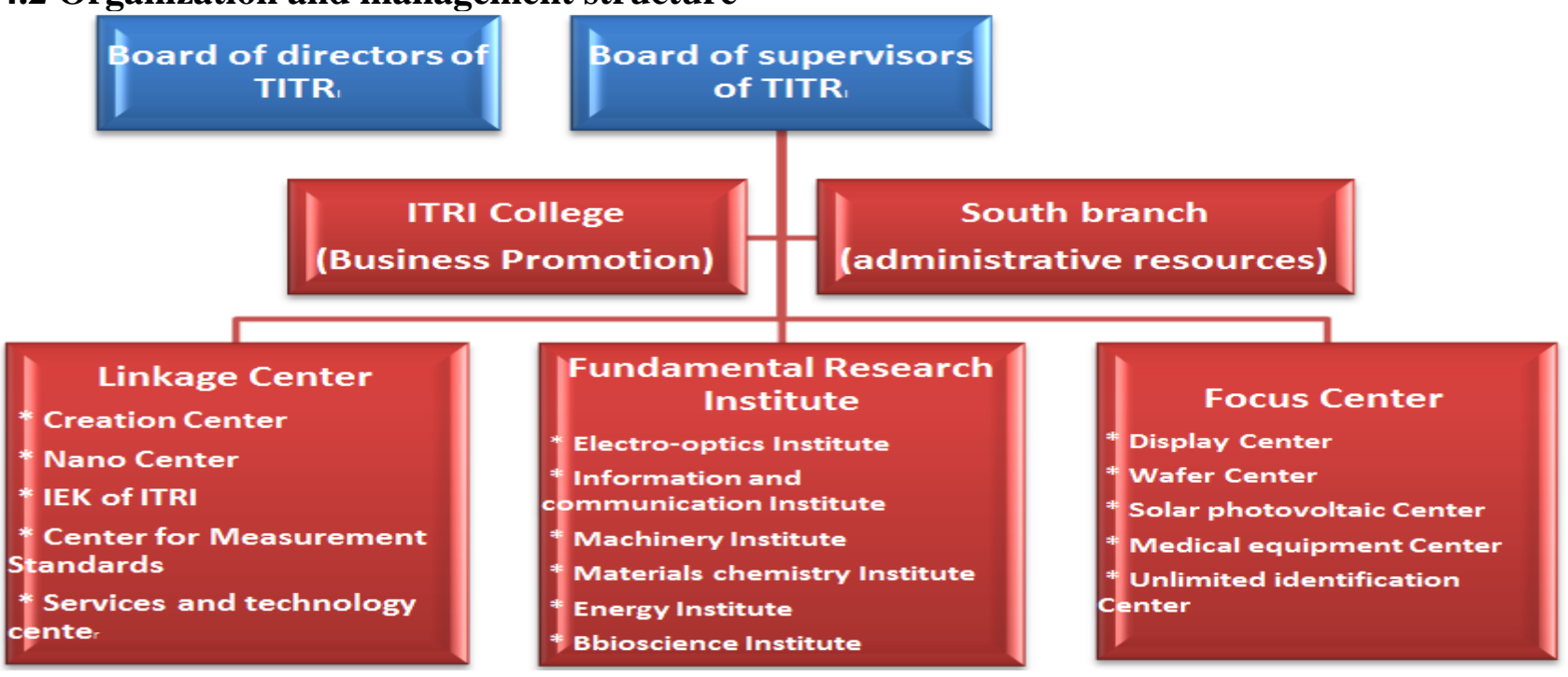

Fig. 1. Organization and management structure of TITRI

As shown in Figure 1, the core business institutions of TITRI have six departments and two big centers, to work around the pillars of the three groups of the R\&D career, technical tasks, and professional services. Basic Research Institution focuses on core technology, the main technology leading and diffusion; Focus Center is mainly engaged in the integration of internal innovation resources, to quickly seize the commanding heights of new technology; Linkage Center mainly integrates administrative services, consulting, technology transfer and other departments, to provide various services for the TITRI.

4.3 Operating mechanism. First, funding mechanism. In the early 10 years of TITRI (from 1973 to 1983), the government provided adequate and stable funding subsidies, which accounted for about $60 \%$ of the cost of ITRI. However, the TITRI has independent management and operation rights in determining the professional direction, research activities and business strategy. To 
promote scientific research, it provides related services through industry later to achieve balance in the absence of government subsidies and a slight surplus situation.

Second, R\&D project selection mechanism. Industry oriented, early intervention in the industry is an important way to select R\&D projects. With the upgrading of industrial capacity, TITRI research $\&$ development projects are gradually integrated, with a special emphasis on forward-looking. For those who are expected to be more sustainable and innovative industries, invest more resources.

Third, technology research \& development mechanism. Its R\&D mechanisms include self-developed, technology introduction, and cooperation with industry, academia and other forms of research, focusing on forward-looking and common application technology research and development. TITRI has established extensive contacts with academia and industrial circle. Its projects can not only be carried out in similar research institutions, but also cooperate with enterprises. Technical staff exchanges are even more so, it encourages R\&D personnel to establish technology-based enterprises.

Fourth, technology diffusion mechanism. The technology diffusion of TITRI mainly includes technology transfer, Spin-off Company and incubation of new enterprises. Technology transfer mainly aims at the common technology for a number of enterprises and the industry that has not yet undertake the object of forward-looking technology. Spin-off Company quickly brings new technology into the industry. Whoever meets the requirements of the high-tech venture individuals and the new company within 18 months of establishment can apply to enter into the incubator center of TITRI, and incubation period is 3 years. The Institute provides the venue and part of the initial investment, as well as business consulting, legal information services.

4.4 Main contribution. First, it enhances the technical strength of Taiwan industry. TITRI takes enterprises' demands as consideration to carry on the technical research and development and to transfer the advanced technology to the industry in various ways, which drives the establishment and the development of Taiwan high-tech enterprises. At the same time it has trained a large number of outstanding technical personnel. Second, it has promoted Taiwan to achieve industrial restructuring, through the development of key technologies to transform the industrial structure and formation of industrial clusters. Third, it has promoted institutional innovation of Taiwan industry. The establishment of TITRI itself is a major institutional innovation. It is defined as a legal body of financial group, that is, a legal person based on certain purpose property, and the main form of which is funds, avoiding it to become inefficient government agencies; Spin-off Company is set up to make it appropriate at the right time listed equity, and continually to get funding support from capital markets.

\section{The promotion of Industrial Technology Research Institute on technology transfer}

5.1 Technical marketing promotes successful commercialization of scientific and technological achievements. For mature scientific and technological achievements, on the one hand, it should be actively strived to incorporate national or local scientific and technological achievements promotion plan, which can enhance the user's trust and the reputation of ITRI; On the other hand, the popularization speed should be promoted of mature scientific and technological achievements. Mature technological results have been developed over a long period of time with a shorter life cycle. If the conversion speed does not be accelerated, it is likely to be copied and faced with the elimination. For the pilot achievements, improve the technical factors of the product itself, as well as design, maintenance and after-sales service to accelerate commercialization of such results. For theoretical achievements, it conducts the market research to determine whether it meets market demand, and then organizes the development and investment according to the situation, so that it will reach the pilot stage.

5.2 Promote industrialization of technological achievements. ITRI is an institutional group that provides specialized services for industrialization of scientific and technological achievements, focusing on the whole process from creativity, trial to manufacturing service. Further extend the industrial chain to both ends, the front extends to the creative, R\&D stage, and then extended to the 
specific realization of the product link, including large-scale production, new product marketing, etc. After the successful development of ITRI, the first hope is that the results can be successfully translated into products (commercialization stage); second, runs the product into an industry (industrialization stage), in this stage, the transformation of scientific and technological achievements into commodities are connected to each other, which constitutes the whole process of transforming scientific and technological achievements into commodities.

5.3 As a new form of industry university research cooperation, promote the transformation of scientific and technological innovation achievements. The development process of ITRI is closely related to the cooperation and the joint efforts among governments, enterprises, universities and research institutes. Enterprises provide market information and funds to ensure practical application value of the research results of ITRI. In return, the ITRI will apply its research results to enterprises in priority, and it provides technical support for enterprises and helps enterprises develop high-tech personnel. Abundant scientific research human resources in Colleges and universities are the guarantee of scientific research of ITRIs. The government provides a sound policy environment for the development of ITRIs.

\subsection{Promote the development of national science and technology innovation system}

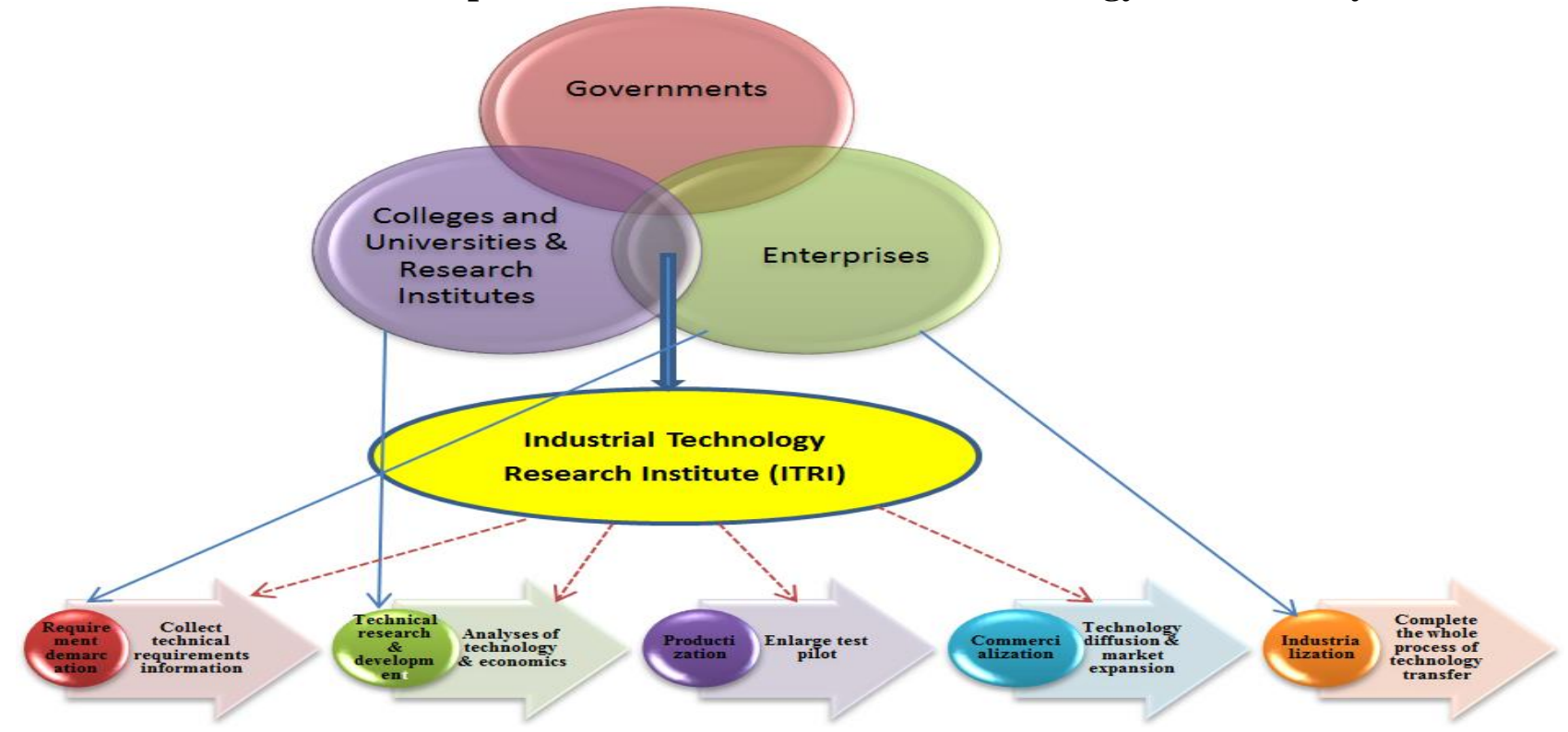

Fig. 2. Science \& technology innovation system taking ITRI as the center

The core of national innovation system is the circulation of science and technology knowledge in one country. Under the government's policy support, plans to establish intermediaries through the innovative industry university research cooperation plan and network. The national innovation system consists of enterprises, universities and scientific research institutions, and the core function of which is to promote enterprise innovation and technological progress. The development mode of ITRI emphasizes the innovation cooperation among enterprises, universities and research institutions, and the government support and guidance, so that the science and technology innovation system can be constructed, with ITRI being the center.

As shown in Figure 2, the top part is the cooperation mechanism under the mode of ITRIs. The ITRIs is established by governments, enterprises, universities and research institutes, which will integrate all resources to promote scientific and technological innovation. The bottom part shows the scientific achievements from the demand to the application of the results, respectively going through the demand definition stage, research and development stage, pilot stage, commercialization or industrialization stage under the mode of ITRI. Each stage is connected with each other, which is an organic, indivisible whole. 


\section{Conclusion}

The world has entered a new economic era driven by innovation, where innovative resources are accelerating the layout of the world and innovation globalization has become a trend. In the context of innovation globalization, knowledge and technology become products and are gradually being industrialized. Knowledge, technology, talents and other innovative resources are accelerating global mobility and layout. At present, China's economic development needs to vigorously promote scientific and technological innovation, to integrate all aspects of power, promote cooperation in research, accelerate transformation of scientific and technological achievements, and promote scientific \& technological innovation technological development to promote economic development. ITRI can play a positive role in promoting production and research cooperation, accelerating the transformation of scientific and technological achievements, and promoting scientific and technological innovation, so it should be fully paid attention to. We should actively rely on the mode of ITRI to promote the construction of local science and technology competitiveness in order to improve the competitiveness of China's science \& technology and economy.

\section{Acknowledgement}

This research was financially supported by Jinan Philosophy and Social Science Program (Grant NO. JNSK16C25) and Shandong University of Science and Technology Domestic Visiting Scholar Project (2015).

\section{References}

[1]H. Li and P. Peng, The role and position of Industrial Technology Research Institute in China's scientific and technological innovation system, Science \& Technology Progress and Policy, vol.2, pp. 38-41, 2008.

[2]M. Yang, Z. Yu and R. Tian, Practice and reflection on the transformation of scientific and technological achievements in colleges and universities by Industrial Technology Research Institute, Forum on Science and Technology in China, vol.3, pp. 115-119, 2009.

[3]P. Chen and J.Li, The development mode of Taiwan Industrial Technology Research Institute and its enlightenment, Industrial Engineering and Management, vol.34, pp. 123-128, 2010.

[4]B. Ye, The Industrial Technology Research Institute innovation mode research based on technology transfer aggregate model (Doctoral dissertation), Southwest Jiaotong University, China. 1997. 